\title{
PERCEPÇÕES SOBRE ENVELHECIMENTO HUMANO E QUALIDÁDE DE VIDA ATRAVÉS DO DISCURSO DE ALUNOS IDOSOS DE UMA UNIVERSIDADE ABERTA PARA A MELHOR IDADE
}

\section{PERCEPTIONS OF HUMAN AGING AND QUALITY OF LIFE THROUGH THE DISCOURSE OF ELDERLY STUDENTS FROM AN OPEN UNIVERSITY FOR SENIOR CITIZENS} \author{
Márcia Maria de Medeiros*
ORCID: https://orcid.org/0000-0002-1116-986X \\ Regina Maria Lima Carbonaro** \\ ORCID: https://orcid.org/0000-0003-2752-0017 \\ Márcia Regina Martins Alvarenga*** \\ ORCID: https://orcid.org/0000-0003-1367-6475 \\ Aline Nunes Menezes**** \\ ORCID: https://orcid.org/0000-0003-1233-8511 \\ Luiz Alberto Ruiz da Silva**** \\ ORCID: https://orcid.org/0000-0002-3257-1196
}

\section{RESUMO:}

O objetivo deste artigo é compreender as percepções sobre o envelhecimento humano e a qualidade de vida no discurso de idosos que participam do projeto de extensão Universidade Aberta para a Melhor Idade, voltado para a terceira idade, desenvolvido na Universidade Estadual de Mato Grosso do Sul, MS. A pesquisa foi desenvolvida com subsídio de um questionário contando com três perguntas relacionadas às percepções que os idosos têm em relação ao projeto de que faziam parte, identificandose, por meio de seus discursos, uma preocupação em se tornarem mais ativos socialmente, terem melhor qualidade de vida, bem como de cuidar mais de sua saúde física e mental. Conclui-se que os idosos que participaram deste projeto alcançaram uma nova perspectiva em relação ao "ser" individual, valorizando sua independência e autonomia enquanto seres humanos e estabelecendo relações consigo mesmos ao se tornarem objetos de seu próprio conhecimento.

Palavras chave: Idosos; Universidade; Extensão.

\begin{abstract}
:
The aim of this article is to understand the perceptions of human aging and quality of life in the discourse of the elderly who participate in the university outreach project Universidade Aberta para a Melhor Idade, aimed at the elderly, developed at the State University of Mato Grosso do Sul. The research was developed, using a questionnaire, with three questions related to the elderly's perceptions in relation to the project they took part in, identifying through their speech, a concern in becoming more socially active, having better quality of life, as well as taking better care of their own physical and mental health. Our results led to the conclusion that the elderly who participated in this project reached a new perspective in relation to the individual "being", valuing their independence and autonomy as human beings, and establishing relationships with themselves by becoming objects of their own knowledge.
\end{abstract}

Keywords: Elderly; University; Outreach project.

\footnotetext{
* Professora da Universidade Estadual de Mato Grosso do Sul (UEMS), Dourados - MS, Brasil. E-mail: medeirosmarciamaria@gmail.com

${ }^{* *}$ Aluna de Graduação Universidade Estadual de Mato Grosso do Sul (UEMS), Dourados - MS, Brasil. E-mail: reginacarbonaro@hotmail.com

*** Professora da Universidade Estadual de Mato Grosso do Sul (UEMS), Dourados - MS, Brasil. E-mail: mrmalvarenga@gmail.com

${ }^{* * * *}$ Aluna de Mestrado da Universidade Estadual de Mato Grosso do Sul (UEMS), Dourados - MS, Brasil. E-mail: alymenzes@gmail.com

***** Professor do Centro Universitário da Grande Dourados (UNIGRANNet), Dourados - MS, Brasil. E-mail: luizalbertoruiz91@gmail.com
} 


\section{Envelhecimento humano e a Universidade Aberta para a Melhor Idade - breves apontamentos}

O processo do envelhecimento é parte inerente da vida dos seres humanos, fase na qual, visando melhorar a qualidade de vida dos sujeitos nele envolvido, é importante considerar diversos fatores, tais como: bem-estar físico e psicológico, nível de independência da pessoa idosa, as relações sociais que ela mantém e cultiva, questões referentes ao seu ambiente de trabalho e lazer, religiosidade, entre outros.

Este processo ainda tem uma relação direta com as questões socioculturais, se transformando e assumindo outras prerrogativas, dependendo do contexto social e cultural em que o sujeito que está envelhecendo se insere. Essas questões vão desde a aceitação da pessoa idosa na comunidade, até hábitos de silenciamento e violência contra esta população. Segundo Schneider e Irigaray (2008), o indivíduo idoso e a sociedade onde ele está inserido estão diretamente relacionados.

A legislação brasileira considera idoso o sujeito a partir dos 60 anos de idade, momento em que (em tese) $)^{1}$ questões biológicas interferem na sua aparência, estado de saúde, entre outros fatores. A relação entre os aspectos cronológicos, biológicos, psicológicos e culturais é fundamental na categorização de um indivíduo como velho ou não (BRASIL, 2003).

Entre as representações sociais ${ }^{2}$ que caracterizam o ser humano enquanto idoso, o aspecto jurídico é uma das mais marcantes: pessoas com mais de 60 anos passam a usufruir de medidas para sua proteção e resguardo, tais como assento preferencial nos meios de transporte coletivo; atendimento prioritário em agências bancárias, supermercados e afins; e passe livre em determinados meios de transportes (BRASIL, 2003).

Outras representações sociais que existem sobre a imagem da pessoa idosa reforçam sobre ela um estereótipo pejorativo que, historicamente, associou-se ao "ser idoso": doenças; dificuldade de locomoção; falta de memória, ou seja, essas representações associam o envelhecimento à ideia de dependência (SILVA, 2008).

Estudos como os de Lopes e Park (2007) destacam que, atualmente, existe uma construção de representações sociais através das quais as imagens de idosos procuram manter em posse desses sujeitos o controle sobre seus corpos, atuando de forma ativa no sentido da realização e satisfação de sonhos e desejos; por outro lado, também coexistem junto a estas representações imagens de velhos pobres, doentes, solitários, assexuados e abandonados à sua sorte. Desse modo, coexistem diferentes representações sobre esta categoria na sociedade brasileira contemporânea.

Mas em que o estudo sobre o envelhecimento humano e as representações e percepções que os sujeitos velhos têm sobre si podem auxiliar no contexto do atendimento das suas necessidades? Este é um questionamento que o presente artigo busca responder. Para tanto, realizou-se uma pesquisa com 6 (seis) idosos participantes do projeto de extensão intitulado Universidade Aberta para a Melhor Idade, da Universidade Estadual de Mato Grosso do Sul.

Para que esta pesquisa fosse realizada, foram convidados a participar idosos que fre-uentam o projeto e são residentes na cidade de Itaporã/MS, vizinha à cidade de Dourados, sede da Universidade Estadual de Mato Grosso do Sul, onde o projeto se desenvolve.

Aos idosos foi apresentado o Termo de Consentimento Livre e Esclarecido (TCLE), no qual constavam todas as informações referentes à pesquisa. Após o aceite das condições propostas no termo, os idosos participantes responderam, por escrito, às seguintes perguntas: a) $\mathrm{O}$ que o(a) levou a ingressar na UNAMI/UEMS?; b) $\mathrm{O}$ que a participação da UNAMI/UEMS representa para você?; e c) O que melhorou ou se modificou na sua vida após o ingresso no projeto? ${ }^{3}$. Para garantir o sigilo em relação às 
identidades dos participantes da pesquisa, utilizamos a seguinte terminologia: Idoso 01 até Idoso 06 no que tange ao processo das respostas e sua consequente análise. As falas dos idosos participantes podem ser vistas no Anexo 1.

A atividade proposta nesta pesquisa foi aprovada pelo Comitê de Pesquisa com Seres Humanos da Universidade Federal de Mato Grosso do Sul (UFMS), sob o protocolo 38881414.0000.0021.

\section{Percepções sobre envelhecimento humano e qualidade de vida no discurso dos idosos que participam do projeto UNAMI/UEMS}

As questões que envolvem o envelhecimento humano, suas representações e as percepções que os sujeitos velhos possuem em relação a si, de acordo com Goyaz (2003), constituem aspecto determinante para a construção de condutas visando o planejamento de ações que promovam um envelhecimento saudável e bem-sucedido, no sentido da efetiva integração do idoso ao contexto social onde ele está inserido.

A autora aponta que algumas destas questões estão postas em práticas como: atividades físicas apropriadas para sua condição, alimentação saudável, espaço para lazer, bom relacionamento social, liberdade de expressão e criação (GOYAZ, 2003). Somados a isso, o amor, o carinho e o reconhecimento das contribuições do idoso para a sociedade, bem como da sua capacidade de amar; podem impulsionar a felicidade, o bem-estar e, consequentemente, a longevidade desse cidadão (VELLAS, 2009).

Outros autores colocam como a organização de práticas integrativas pode gerar ações que levam ao envelhecimento saudável, as quais envolvem elementos que tangenciam o trabalho e a educação, possibilitando que os idosos percebam nessa fase da vida um lócus produtivo e, portanto, positivo no sentido de verem-se como sujeitos que contribuem com o status quo (DEBERT, 1996; USSUELI, 2012; CACHIONI, 2003).

No estado de Mato Grosso do Sul, existem espaços próprios que possibilitam aos idosos o desenvolvimento destas prerrogativas, fortalecendo sua perspectiva enquanto sujeitos de seu processo de vida. Entre esses espaços de ação está a Universidade Aberta para a Melhor Idade (UNAMI), projeto de extensão desenvolvido pela Universidade Estadual de Mato Grosso do Sul (UEMS) e do qual o curso de graduação em Turismo faz parte enquanto integrante, através da ação de professores envolvidos no trabalho com os idosos.

O Projeto UNAMI da UEMS foi criado no ano 2013, com o intuito de resgatar a autoestima dos idosos que participam da iniciativa. A ideia é oferecer oportunidades para que eles possam sentir-se produtivos, úteis, ativos e agentes da comunidade na qual fazem parte. $\mathrm{O}$ projeto contribui principalmente para o resgate da cidadania e do espaço político desses indivíduos.

Em 2013 e 2014, foram desenvolvidas ações que os próprios idosos avaliaram com resultados positivos. A partir dos dados obtidos junto ao público-alvo do projeto ${ }^{4}$, ele foi totalmente reformulado, incluindo o nome, por solicitação dos participantes, passando a ser chamado de Universidade Aberta para a Melhor Idade (UNAMI/UEMS).

A reformulação incluiu, ainda, ampliação do projeto pedagógico de dois para quatro anos e a participação de outras áreas do conhecimento, como Ciências Agrárias, Ciências Econômicas e Pedagogia. Os idosos que participaram desta pesquisa fazem parte do programa de extensão Universidade Aberta para a Melhor Idade da Universidade Estadual de Mato Grosso do Sul (UNAMI/EUMS), realizado pelo curso de graduação em Enfermagem da mesma instituição e conta com o apoio interdisciplinar de vários outros cursos, como Turismo, Direito, Letras, Engenharia Ambiental e Economia. 
Já fizeram parte do quadro do programa, na condição de ministrantes de oficinas, professores de outras Instituições de Ensino Superior (IES) e da área de Biomedicina. Os participantes do programa UNAMI/UEMS permanecem em contato com atividades acadêmicas por 4 anos, sendo os dois primeiros anos entendidos como ciclo básico (Ano I Processo de envelhecimento como condição humana; Ano II - Velhice, Gênero e Sociedade); e os dois últimos (Ano III - O envelhecimento e a aprendizagem; Ano IV - Comunicação, interação e evolução: expectativas e perspectivas), como estudos aprofundados.

Dentro do período de quatro anos, são também desenvolvidas atividades pedagógicas, culturais, sociais e de lazer. Este breve histórico foi proposto com o intuito de que se compreenda o universo de atividades que compõem o quadro do projeto de extensão UNAMI/UEMS, a fim de entender as percepções sobre o envelhecimento humano e a qualidade de vida no discurso dos idosos que participam do mesmo.

Atualmente, ao todo participam do projeto 45 idosos, dos quais 6 responderam ao questionário (4 mulheres e 2 homens), todos residentes no município vizinho de Itaporã, MS, professores aposentados da rede pública estadual de ensino. Estes idosos foram escolhidos por fazer parte do projeto desde o início (no ano de 2013). As idades desse público variam de 60 a 72 anos.

Quando perguntado sobre o que levou ao ingresso no projeto UNAMI/UEMS, o Idoso 01 respondeu que tomou conhecimento do curso devido ao Sindicato dos Professores da cidade e julgou profícua a sua participação em algo que lhe possibilitasse continuar aprendendo e melhorando seus conhecimentos. Ademais, chamou a sua atenção a possibilidade de conviver com pessoas com ideias diferentes, além de fazer novas amizades.

A resposta do Idoso 04 corrobora esta assertiva, pois revela um desejo de continuar incluído na sociedade a partir da convivência com um grupo de amigos, oportunizando a troca de experiências e promovendo, assim, a melhora da qualidade de vida. Da mesma forma, o Idoso 05 revela, em sua resposta, que ingressar em um projeto como a UNAMI/UEMS lhe permitiu adquirir conhecimentos que lhe oportunizaram uma melhor qualidade de vida, bem como exercitar as questões que envolvem a memória.

Os idosos participantes da pesquisa fazem parte de um contexto abordado por Silva (2008), quando a autora afirma não ser mais possível associar a questão do envelhecimento à ideia de decadência ou incapacidade produtiva. De acordo com a autora, as bases propostas pela gerontologia buscaram articular uma nova representação da pessoa idosa, associando esta fase da vida a experiências relacionadas a um processo de envelhecimento positivo, atrelado à convivência, às trocas de experiência e ao contínuo aprendizado.

Ao responderem a questão número 01, os Idosos 02 e 06, respectivamente, trouxeram outros pontos importantes para o debate. Para o Idoso 02, a aposentadoria não pode ser considerada a etapa final da vida. Na opinião deste participante, é uma felicidade chegar à idade de aposentar-se com saúde e em condições de aproveitar esta fase. O Idoso 06 amplia este escopo de pensamento ao afirmar que a solução pós-aposentadoria não era a estagnação. Ambos trouxeram, em seus discursos, elementos que permitem compreender que o projeto UNAMI/ UEMS permitiu uma continuidade nas ações cotidianas, oportunizando crescimento pessoal.

Estas respostas trazem em si um novo sentido para a ideia de aposentadoria; se anteriormente o sujeito aposentado carregava um estigma de incapacidade, que consolidava no imaginário cultural uma premissa negativa em torno do envelhecimento (SILVA, 2008), as prerrogativas agora trazem outra situação e passam a exigir um novo posicionamento em relação a esta categoria, demonstrando a existência de sujeitos que querem continuar a existir em suas subjetividades (FOUCAULT, 2005), exercendo o seu papel de protagonistas da sua história.

A pergunta número 02 buscou entender o que a participação no projeto representava para cada um dos idosos envolvidos. Dentre as respostas, salienta-se que os idosos percebem o ambiente da Universidade como um espaço para o convívio, um lugar onde 
amizades podem ser estabelecidas, fazendo com que floresça um sentimento de esperança e de alegria (respostas dos Idosos 01, 02 e 04).

Para o Idoso 03, participar do projeto significa alcançar um espaço onde haja momentos de distração e de exercício tanto do corpo quanto da mente, salientando a necessidade de ocupar o tempo para que ele não se esvaia nem seja inócuo. Percebe-se, nesta fala, um desejo de continuidade no sentido do bom aproveitamento da vida, no sentido de entendê-la plena, independente do fator idade.

Outro ponto a ser ressaltado nas respostas diz respeito ao fato de que os participantes da pesquisa percebem o projeto como um momento no qual o convívio social prazeroso pode ser resgatado, a partir da convivência com outros idosos e também do aprendizado proporcionado pelas atividades realizadas no projeto (TAAM, 2008), as quais, segundo o Idoso 05 , possibilitam melhor qualidade de vida.

Para o Idoso 06, o projeto desenvolvido pela UEMS possibilita a integração entre as gerações, pois ao realizá-lo a Universidade estende seus objetivos para além do ensino regular da graduação e faz com que os idosos participantes do projeto retomem uma condição de protagonismo, mostrando o quanto eles contribuem para com a sociedade. Tal processo resgata a autoestima e devolve aos participantes sua condição de cidadãos.

Nesse mesmo sentido, o trabalho de Campos (2010) ressalta a importância da convivência entre gerações e do empoderamento ${ }^{5}$ que este processo acarreta aos idosos, quando narra a experiência promovida pela Faculdade de Comunicação da Universidade de Sevilha. Segundo o autor, existe a necessidade de a Universidade não se ater apenas ao ensino regular e objetivo, mas também se colocar à disposição da sociedade e contemplar, em seu processo educativo, assuntos que se referem à própria vida.

Quando perguntado sobre o que melhorou ou se modificou em sua vida após o ingresso no projeto UNAMI/UEMS, o Idoso 01 foi bastante objetivo ao responder que a participação no projeto possibilita a quebra da rotina, além de proporcionar uma continuidade em seu processo de vida. Através desta fala se percebe o quanto a sociedade entende a aposentadoria como um momento em que, ao afastar-se da vida de trabalho, o sujeito aparentemente também se afasta do próprio ato de viver, conforme estudo de Silva $(2008)^{6}$.

O Idoso 02 entende que o projeto possibilita uma nova percepção sobre o mundo, fortalecendo a esperança em relação à possibilidade de coexistir mesmo diante das diferenças entre as pessoas. Para ele, a proposta realizada pela UNAMI/UEMS fomenta a possibilidade do respeito mútuo e da convivência da diversidade, promovendo maior qualidade de vida.

Os Idosos 03, 05 e 06 fizeram referência à prática de atividade física, que é uma das atividades desenvolvidas no projeto. Para eles, este momento contribui para a saúde física e mental, promovendo melhoria da qualidade de vida, pois resgata a mobilidade dos sujeitos, devolvendo a eles autonomia de movimentos, que se traduz por autonomia em suas atividades cotidianas (TAAM, 2009).

A tônica dos discursos deixa entrever que os participantes passaram a se preocupar mais consigo mesmos, sentindo-se estimulados positivamente tanto pelos conteúdos desenvolvidos quanto pelas atividades propostas (passeios, aulas de Educação Física, de Espanhol). Estas premissas acarretaram o aumento da qualidade de vida e se traduziram por sentimentos de felicidade e de autoestima (SANTIN; BETTINELLI; BENINCÁ, 2007).

Partindo das premissas desenvolvidas por Furter (2013), percebe-se que o exercício educativo proposto pela UNAMI/UEMS abarca a ideia da educação permanente, ou seja, a possibilidade de o sujeito educar-se durante toda a sua trajetória de existência. Neste sentido, a educação surge "como um princípio ativo [...]" (FURTER, 
2013, p. 76), que impacta na vida das pessoas, produzindo mudanças, as quais podem ser tanto subjetivas quanto objetivas.

No sentido da subjetividade, essas mudanças significam a melhoria da qualidade de vida dos sujeitos participantes do processo, o alcance de novas percepções em relação a si mesmos e ao mundo que os cerca, permitindo com isso a elevação do capital social das comunidades nas quais este sujeitos estão inseridos.

No sentido da objetividade, este contexto permite repensar o sistema educacional, possibilitando a troca de experiências, no caso deste projeto entre sujeitos idosos e não idosos, efetivando, a partir daí, normas de convívio que estimulam o respeito à diversidade e o estímulo à solidariedade, considerando a alteridade e a aceitação das diferenças.

\section{Considerações Finais}

Foi possível perceber, com a execução desta pesquisa, que o projeto UNAMI/ UEMS funciona como espaço que promove a inclusão dos idosos que dele participam, fazendo com que estes sujeitos reafirmem o protagonismo de suas vidas e reforcem em si a ideia do cuidado de si.

A partir das respostas obtidas, observa-se que o discurso dos sujeitos alcança uma nova perspectiva em relação ao "ser" individual, a qual carrega, enquanto componentes: o valor que cada um atribui à sua singularidade e à sua independência; a valorização das atividades que são inerentes à sua vida privada, tais como as relações de amizade que podem desenvolver; e, por fim, as relações que estes sujeitos estabelecem consigo mesmos ao se tornarem objeto de seu próprio conhecimento.

Tais práticas são carregadas de um processo de subjetivização, permitindo que os idosos que participam do projeto construam novas percepções pessoais em relação a quem eles são; as suas experiências de vida; e as suas ações na sociedade. Esta premissa faz com que o grupo articule novas formas relativas à arte da sua própria existência e adote diferentes padrões de comportamento em relação ao mundo em que vivem.

$\mathrm{Na}$ condição de exercício educativo, não existe um momento propício para que este cuidado em relação a si se inicie, pois ele se caracteriza por ser uma prática que traz, intrínseca à sua ação, a necessidade de se aprender a viver, o que acontece enquanto houver vida. $\mathrm{O}$ que deve ser compreendido é que este processo deve tornar-se um hábito e um exercício cotidiano e permanente.

Assim, podemos dizer que este tipo de atividade pode e deve ser compreendida como uma ferramenta para o processo de educação de idosos, sendo utilizada como estratégia no projeto desenvolvido pela UNAMI/UEMS, levando, por consequência, ao aprimoramento da prática do cuidado de si por parte dos idosos que dele fazem parte.

O quanto isso é benéfico para os participantes pode ser visto a partir das suas falas, das ações e da sua afirmação enquanto sujeitos de si, com sua própria forma de ver o mundo e com sua própria forma de ser no mundo, conforme demonstraram os dados desta pesquisa.

Com este trabalho, nos propusemos a trazer para a discussão e para a reflexão um assunto que deveria ser colocado na pauta de debate dos governos em nível mundial, devido ao crescimento constante da população idosa. Percebemos que, no contexto no qual a sociedade está inserida, faz-se necessário atender às demandas crescentes por parte desta população, ofertando ações que melhorem a sua qualidade de vida, como é o caso do projeto UNAMI/UEMS. 


\section{Referências}

BRASIL. Lei ${ }^{\circ} 10.741$ de $1^{\circ}$ de outubro de 2003. Dispõe sobre o estatuto idoso e dá outras providências. Diário Oficial da União. Disponível em:

$<$ http://www.planalto.gov.br/ccivil_03/leis/2003/L10.741.htm>. Acesso em: 05 set. 2019.

CACHIONI, M. Quem educa o idoso: um estudo sobre professores de universidades da terceira idade. Campinas: Alínea, 2003.

CAMPOS, Pedro Celso. Jornalismo Ambiental, Envelhecimento Demográfico e Universidade Aberta à Terceira Idade: A tese do Empoderamento. Revista Galáxia, São Paulo, n. 19, p. 291-305, jul. 2010. Disponível em:

https://revistas.pucsp.br/galaxia/article/view/2081/2210. Acesso em: 05 set. 2019.

DEBERT, G. G. A invenção da terceira idade e a rearticulação de formas de consumo e demandas políticas. Revista Brasileira de Ciências sociais, s/v, n. 34, p. 1-16, 1996. Disponível em: <http://www.anpocs.com/images/stories/RBCS/34/rbcs34_03.pdf>. Acesso em: 05 set. 2019.

FOUCAULT, M. História da Sexualidade: o cuidado de si. Rio de Janeiro: Edições Graal, 2005.

FURTER, P. O planejador e a educação permanente. Cadernos de Pesquisa, s/v, n. 27, p. 73-99, 2013. Disponível em: <http://publicacoes.fcc.org.br/ojs/index.php/cp/article/view/1731/1715>. Acesso em: 15 mai. 2020.

GOYAZ, M. Vida ativa na melhor idade. Revista UFG, v. 5, n. 2, 2003. Disponível em: $<$ http://www.observatorionacionaldoidoso.fiocruz.br/biblioteca/_artigos/47.pdf $>$. Acesso em: 05 set. 2019.

HEIDEGGER, M. Ser e tempo Parte I. 15. Ed. Petrópolis: Vozes, 2005.

HOROCHOVSKI, R. R.; MEIRELLES, G. Problematizando o conceito de empoderamento. In: SEMINÁRIO NACIONAL MOVIMENTOS SOCIAIS, PARTICIPAÇÃO E DEMOCRACIA, 2., 2007, Florianópolis. [Anais]... Florianópolis: UFSC, 2007.

LOPES, E. S. L.; PARK, M. B. Representação social de crianças acerca do velho e do envelhecimento. Estudos de Psicologia, v. 12, n. 2, p. 141-148, 2007.

MOSCOVICI, S. A representação social da psicanálise. Rio de Janeiro: Zahar, 1978.

SANTIN, J. R.; BETTINELLI, 1. A; BENINCÁ, C. R. Envelhecimento Humano: Cuidado e Cidadania. 1. ed. Passo Fundo: Universidade de Passo Fundo, 2007.

SCHNEIDER, R. H.; IRIGARAY, T. Q. O envelhecimento na atualidade: aspectos cronológicos, biológicos, psicológicos e sociais. Estud. psicol., Campinas, v.25, n.4, p.585-593, 2008. Disponível em: https://www.scielo.br/scielo.php?pid=S0103166X2008000400013\&script=sci_abstract\&tlng=pt. Acesso em: 05 set. 2019.

SILVA, L. R. F. Da Velhice à Terceira Idade: o percurso histórico das identidades atreladas ao processo de envelhecimento. História, Ciências: Saúde. Manguinhos, Rio de Janeiro, v. 15, n. 1, p. 155-168, 2008.

TAAM, R. A educação do idoso: Uma questão contemporânea. In: ALTOÉ, A. (org.).

Temas de educação contemporânea. Cascavel: Edunioeste, 2008. p. 45-56. 
TAAM, R. A educação não formal do Idoso em universidades da Terceira Idade e Centros de convivência. In: PARK, M. B., GROPPO, L. A. (org.). Educação e Velhice. Holambra/SP: 2009. p. 39-49.

USSUELI, C. A universidade aberta à terceira idade no cenário educacional brasileiro. 2012. Disponível em: <http://www.dfe.uem.br/TCC/Trabalhos_2012/CLARISSA_USSUELI.PDF>. Acesso em: 05 set. 2019.

VELLAS, P. As Oportunidades na Terceira Idade. Paris: Stock, 1974. Tradução e notas Claudio Stieltejs e Regina Taam. Maringá: Eduem, 2009.

\footnotetext{
Notas

${ }^{1}$ Vale ressaltar que tais mudanças não acontecem somente aos 60 anos. Elas fazem parte de um conjunto e de um contexto que se inicia quando o indivíduo nasce, partindo de uma prerrogativa existencialista, conforme Heidegger (2005).

${ }^{2} \mathrm{O}$ conceito de representação social neste trabalho parte da prerrogativa de Moscovici no campo da Psicologia Social De acordo com este autor, a psicanálise, quando tomada por uma teoria científica complexa difundida em uma determinada cultura, se transforma, ao mesmo tempo em que modifica o universo social que a cerca, modificando também a visão que as pessoas têm de si e do mundo ao seu redor (MOSCOVICI,1978).

3 As respostas destas perguntas seguem em anexo, após as Referências que compõem o escopo deste artigo.

4 No período em questão o projeto recebia o nome de Universidade Aberta para a Terceira Idade (UNATI).

5 O conceito de empoderamento utilizado neste artigo é definido por Horochovski; Meirelles (2007) como sendo o processo através do qual os sujeitos desenvolvem habilidades e agregam recursos que possibilitam aos mesmos adquirirem autonomia, capacidade de ação e decisão, permitindo-lhes visibilidade e fortalecimento da cidadania.

${ }^{6}$ No discurso do Idoso 01 isso fica perceptível, quando diz que: “Aposentar sim, mas não para a vida."
} 
ANEXO 1

Pergunta 01: O que o(a) levou a ingressar na UNAMI/UEMS?

Idoso 01 - "Fiquei sabendo do curso pelo Sindicato dos professores e como já estava aposentada, achei por bem buscar uma atividade que me colocasse participando de algo que pudesse continuar aprendendo e assim melhorar ou ampliar meus conhecimentos e também ter convivio com pessoas de ideias diferentes e fazer novas amizades".

Idoso 02 - "Aposentadoria jamais poderá ser considerada "fim de vida”. Feliz de quem chega à idade de aposentar-se com saúde, tendo construído condições favorável a uma aposentadoria digna. É possível olhar à frente e descobrir espaço onde possa continuar vivendo com dignidade. Foi assim, para mim, a descoberta da U AMI/UEMS. Quem sempre conviveu nesse meio "professor aluno - aluno professor", vê, agora, mais ampliado este campo, com outras categorias e mais pessoas, e mais alunos e alunas, isto nos faz crescer".

Idoso 03 - "Foi a convite da professora Cleonice, que já estava frequentando, $e$ que depois passei a frequentar. Gostei muito, já faz quase 4 anos".

Idoso 04 - "O que me levou ingressar na U AMI foi o desejo de continuar incluído na sociedade com um grupo de amigos que tivessem os mesmos interesses e que no dia a dia a oportunidade de trocarmos experiências e melhorássemos cada vez mais a nossa qualidade de vida”.

Idoso 05 - "Ingressei na U AMI com o objetivo de adquirir conhecimentos que possam auxiliar-me a ter uma melhor qualidade de vida, bem como exercitar a memória”.

Idoso 06 - "Entendemos que ficar parado não era a solução. Somos uma geração que busca sempre o novo. E ficamos sabendo que, em Campo Grande, tem a UMI, através de uma amiga que estuda lá e estávamos prontos a conhecer esta instituição. Quando surgiu um anúncio no jornal que chamou nossa atenção, que seria implantado um projeto para a MI/Melhor Idade na UEMS, nos organizamos e que estamos há 4 anos. Valeu!!!”.

Pergunta 02: O que a participação da UNAMI/UEMS representa para você?

Idoso 01 - "Como disse acima, aprendizado, convívio salutar com os outros alunos e - por que não - lazer!".

Idoso 02 - "A vivência de amizades sem cobranças, nem grandes responsabilidade, nos dá alegria e prazer ao sentir o pulsar dos corações jovens na busca de afirmações no seu "quer ser", e cresce a nossa esperança de que sejam felizes no seu bem-fazer".

Idoso 03 - "A minha participação levou-me a entender que, na nossa idade, temos que nos distrair de diversas formas, exercitar nossa mente, nosso corpo, fazer novas amizades etc. ão deixar o tempo passar em vão. É o que a U AMI representa para mim. "Uma dádiva de Deus"”.

Idoso 04 - "A participação da U AMI representa para mim um convívio social prazeroso e tranquilo, onde fazemos novas amizades e aprendemos novas experiências intelectuais. Como, por exemplo, o curso de espanhol". 
Idoso 05 - "Representa muito, estou satisfeita com os conteúdos proporcionados pelos nossos professores, são importantíssimos e estão contribuindo para que eu possa ter realmente uma melhor qualidade de vida".

Idoso 06 - "Uma instituição que se propõe estender seus objetivos além do ensino regular, buscando integrar gerações. Um novo olhar para aqueles que contribuíram e ainda contribuem para a sociedade, com certeza resgatando vidas".

Pergunta 03: O que melhorou ou se modificou na sua vida após o ingresso no projeto?

Idoso 01 - "Hoje tenho objetivo de toda $4^{a}$ feira sair da rotina doméstica e participar do projeto. Aposentar sim, mas não para a vida".

Idoso 02 - "Os horizontes se abrem para a percepção de um mundo que, apesar do seu aspecto cruel como é visto, fortalece-nos a esperança de que é possível coexistir com as diferenças, as dificuldades, os "quereres" de cada pessoa, respeitando-se mutuamente; qualidade de vida constituída por todos e para todos. Recordando aqui: os passeios, as visitas, o esporte e o lazer etc.”.

Idoso 03 - "Para mim melhorou bastante, pois lecionei 42 anos, sempre no meio da garotada, sentindo aquele clima bom de ensinar e aprender ao mesmo tempo. Esse projeto veio a calhar na minha vida, porque me sinto bem, como se estivesse em minha sala de aula, revivendo, aprendendo coisas boas. Fico alegre quando vou às quartas-feiras para aula. As aulas de Educação Física são ótimas, com a Prof ${ }^{a}$ Lurdes. E agora, com as aulas de espanhol, melhorou muito mais".

Idoso 04 - "Aprendi a ter novo olhar sobre a melhor idade, e que é necessário mais medidas para solucionar os desafios que estão surgindo, como o aumento populacional dos idosos. Como, por exemplo, o investimento na saúde, no lazer, investimento na qualidade de vida".

Idoso 05 - "Após o meu ingresso na $U$ AMI, passei a me preocupar mais com a minha saúde, estimulada pelos conteúdos estudados e também as aulas de Educação Física vieram contribuir muito com relação à minha saúde física e mental. Sinto-me muito feliz nos momentos de lazer, dos quais faço parte na U AMI, junto com os colegas".

Idoso 06 - "Todo o processo estabelecido desde o primeiro ano veio agregar novos conhecimentos com profissionais gabaritados dentro de sua área. Prática de estar sempre em movimento, seja na área social, intelectual e física. Agradecimento às aulas da professora Lourdes, que através dos exercícios pude resgatar minha mobilidade com mais eficiência. Autoestima sempre estimulada. Obrigada!!!”. 